\title{
SOCIAL DIALOGUE AND PARTNERSHIP IN VOCATIONAL EDUCATION AND TRAINING
}

\author{
Dr. Zoran Velkovski, University “Ss. Cyril and Methodius”, Faculty of philosophy, Skopje, \\ Republic of Macedonia, E-mail: zorve2010@yahoo.com \\ Dr. Elena Rizova, University “Ss. Cyril and Methodius”, Faculty of philosophy, Skopje, \\ Republic of Macedonia, E-mail: elenarizova@fzf.ukim.edu.mk
}

Received: May, 14.2015.

Accepted: June, 01.2015.

Original Article

UDK 377(497.7)

\begin{abstract}
Vocational education and training systems in the Republic of Macedonia have been put under strong pressure for modernisation in the last decades. In addition to economic and political globalisation, technological innovations brought rapid changes in the type of jobs and the content of labour in the national economies, which lead to change of the demand for qualifications and new skills on an on-going basis; the open market and migration expanded opportunities for work within and between countries, and the complexity of the demand for new skills on the labour market have dramatically begun affecting and shaping the structure, organisation and content of vocational education and training.

This report is based on the experiences from the collaborative approach applied in the development of the Strategy for Vocational Education and Training in a Lifelong Learning Context for the Republic of Macedonia, implemented through a process of consultation with a broad stakeholder basis. It addresses the participants in the process, the steps undertaken to ensure involvement of stakeholders and ultimately ownership over the process (or its components), the obstacles encountered and steps undertaken to address them, the problems, their causes and proposals for preventing and/or eliminating them, as well as the lessons learned and recommendations for further development of the social dialogue and partnership.
\end{abstract}

Keywords: Vocational education and training, Reform, Modernization, Collaborative approach, Partnership.

\section{INTRODUCTION}

Vocational education and training systems in Europe have been put under strong pressure to modernise in the last decades. In addition to economic and political globalisation, technological innovations brought about rapid changes in the type of jobs and the content of labour in the national economies, changing the demand for qualifications and new skills on an on-going basis; the open mar-

Corresponding Author

Dr. Elena Rizova, University "Ss. Cyril and Methodius", Faculty of philosophy, Skopje,

Republic of Macedonia

E-mail: elenarizova@fzf.ukim.edu.mk ket and migration expanded opportunities for work within and between countries, and the complexity of the demand for new skills on the labour market began to dramatically affect and shape the structure, organisation and content of vocational education and training.

Today's global economic crisis introduced and is expected to continue to put additional pressure on vocational education and training. The adaptability of those losing their jobs in an environment of reduction of public and private financing and the ability and flexibility of VET systems to provide sufficient competences and abilities for work mobility and learning to those young persons and adults who are and/or will be in the process of learning remain the most significant challenges facing VET. The extent to which VET systems are able to respond to their new roles and tasks will depend primarily on educational policies, on the ability and readiness to implement best solutions and the ability to efficiently use the resources and capacities at the disposal of the countries in Europe and the world. This task is a huge challenge for the Republic of Macedonia.

In parallel to the need for enhanced economic and political interventions, the country is facing challenges for improving the quality and efficiency of vocational education and training. It is making efforts to harmonise this education system with and adapt it to the standards applied in the countries of the EU.

The dynamic of change in the modern economy is so intense, that it needs permanent monitoring of the situation and quick reaction to emerging needs for new occupational areas and/or profiles. Mutual interdependence of labour and education requires the development of a sustainable early warning and planning system which will assess the impact of new curricula on the labour market and education, and will register and timely respond to the feedback provided by VET clients, students, 
employers, universities, schools and other stakeholders. The development of an efficient and functional model of social dialogue is of exceptional significance for effective and efficient realisation of these goals.

The main purpose of social dialogue is the promotion of consensus building and democratic participation of main stakeholders in VET. Social dialogue, through collective negotiations and consultations, provides the stakeholders with an opportunity to influence the decisions that affect them or that pertain to issues of common interest, by means of consensus building and democratic participation.

Within VET, social dialogue is a vital component in the achievement of the goal of attractive, quality and relevant VET. The implementation of a successfully structured social dialogue has the potential for efficient solving of the key education issues, for practicing of good governance, for improvement of the quality and stability of the VET system and for strengthening its development. VET stakeholders bear the greatest responsibility for the implementation of education reforms or initiatives, and without their full involvement in the key aspects of education policies, such reforms and/or initiatives cannot be fully realised, often failing.

Social dialogue affirms its importance not only in the processes of setting the agenda and aspirations of the country for socio-economic development, but also in the processes of defining the country's strategic directions in education, in the formulation of VET policies, in their implementation, and in the review/ evaluation of the outcomes and impact of the said policies.

Multisectoral interdependence in the functioning of VET places at the forefront the issue of (lack of) success of the social dialogue, as a process that should bring together the interests, needs and potentials of social partners into a platform on which future interventions in VET are based, a platform on which the country's aspirations for socioeconomic development rest. Wise economic growth requires wise (re)designing and functioning of the VET system.

The choice of a model of social dialogue can differ according to how democratic the capacities of the country and how "wise" VET policy-makers are. It varies between centralised, declarative and proactively collaborative.

The centralised model of social dialogue is unidirectional and moves from the centres of power to the social partners. This model establishes the interests and decisions of the central government as a "joint" platform to which social partners should adjust their interests and needs. In the name of a divided majority, all decisions on the development of VET are adopted by a unified minority of political power-holders and/or expert individuals or groups. It does not provide for an opportunity to translate the interests and needs of stakeholders into joint and coordinated action in VET and socio-economic development of the country, and most often it does not reflect the reality, thus ending in failure.

The declarative model of social dialogue addresses the legislative right of social partners to take part in the (re)designing and functioning of VET; representatives of the social partners are part of the process (through bodies, commissions, ad-hoc groups, etc.), which is on-going within the VET system and which has as its goal its improvement and development. Most often, this model of social dialogue is manifested through a large number of signed memoranda of cooperation between those responsible for education policies and social partners or stakeholders. They officially make a commitment to collaborate, which is in essence declarative because it is hardly or very marginally operationalized in practice. Despite the possibility provided by law for social partners to influence the development and functioning of the VET system, their participation is marginalised and is often not reflected in the policy decisions adopted in VET.

The collaborative model of social dialogue is a decentralised model of collaboration and decision-making, providing opportunities for high-quality findings and insight in VET that can improve its development, policy setting and defining of its future goals and activities. It enables active participation of the most relevant stakeholders in the processes of analysing the situation, forecasting future needs, planning, organising and delivering VET and monitoring and evaluating the results. As a practice, this model can be a powerful tool for strengthening the relevance, attractiveness and quality of VET.

If we take a chronological look at the situation in the Republic of Macedonia, we can conclude that all three models of social dialogue appear in full or partially in the development of the country's VET system.

The application of the centralised model of social dialogue characterises the period in which the Republic of Macedonia was part of the former SFRY. Up to 1985, VET was an integral part of the single education system 
and subject to centralised creation of education policies.

With the adoption of the Law on oriented vocational education in 1985, VET became one of the main priorities of policymakers. According to this Law, oriented vocational education was a "constituent part of the single system of associated labour and a significant factor of societal reproduction in the development of manufacturing force, in meeting educational and staffing needs of associated labour and of society as a whole, in the liberation of labour and man, as well as in the holistic development of the individual and progress of the socialist self-government society". (Law on oriented vocational education, Official Gazette of the Republic of Macedonia No. 16 from 22 May 1985)

The business sector or so-called organisations of associated labour were deeply involved in the design of policies and delivery of VET, establishing a close and interactive link between business entities and education providers. This period is characterised by establishment of company education centres/ schools. The thorough involvement of business entities in the formulation of education policies, in the management of education providers and delivery of teaching and learning, including practical teaching and training, creates an impression that a collaborative model of social dialogue was practiced. Such an impression would have been correct, if the social dialogue had been carried out respecting the principles of an open labour market, and if it had not been compromised by the country's economic development policies, especially employment policies.

Economic development in former Yugoslavia was based on a so-called social consensus which required: full employment, free education, free health care and full equality in the distribution of benefits. Creation of education policies was directly conditioned by the commitment to the policy of full employment. Depending on the number of unemployed and the saturation of the labour market with educated persons in a given sector, cabinet decisions were made on decrease of the education offer, or in a worse case, on the temporary pause in the work of specific education institutions. The foundation for this policy was to be found in the understanding that each finalised (graduated) education profile "thrown" onto the labour market by the education system, must be matched by an appropriate labour equivalent, i.e. appropriate job. Thus, it was frequently the case that jobs were invented so as to achieve full employment and/or to employ the population that arrived en masse from the rural into the urban areas, and to employ the huge number of individuals with party membership cards. In such a case, employment of new workers is carried out irrespective of the real, objective needs of the economy. This created the impression of a virtual regulation of the labour market, but in the majority of cases it resulted in a loss of productivity and continuing increase of over-employment as a special form of covert unemployment, which emerged with all its adverse consequences at the transition toward market economy. This brought about an increased number of workers occupying positions for which they lacked the necessary qualification and training, increased number of workers without actual work, decreased power of enterprises, poor utilisation of capacities, increased number of unemployed with qualifications and expertise, etc. The extent of the erroneousness of this policy is best revealed by the fact that in $1986,36.14 \%$ of workers in the social sector occupied jobs requiring higher qualifications. It is evident that the projections of the development of workers, i.e. the matching of the education supply and demand was flawed and lacked a correctly applied collaborative model of social dialogue. (Statistical Yearbook of the Republic of Macedonia, 1992)

The application of the declarative model of social dialogue is characteristic for the period after the independence and adoption of pluralism and market economy. The increase in the number of VET stakeholders (local government, private sector, trade union, chambers, etc.) and the awareness of the need for a dynamic link between the economy and social development and the education supply spurred an enhanced debate on the future of VET, which resulted in involvement of stakeholders in the process of VET policy creation and in the work of education institutions. All this was accompanied by legislative revisions which culminated in the adoption of the Law on vocational education and training in 2006. (Law on Vocational education and training, Official Gazette of the Republic of Macedonia No. 71 from 08.06. 2006)

Stakeholder representatives became part of management bodies of VET schools, albeit without a right to make real decisions, i.e. to vote; they take part in expert commissions and working groups/bodies of government and expert institutions/agencies, they are entitled to declare and voice their interests in VET and to 
undertake initiatives. This period is characterised by the signing of a number of protocols of cooperation, establishment of professional associations and bodies and other initiatives for mutual collaboration. Unfortunately, despite the publicly declared pledges for collaboration and joint creation of VET policies between central authorities and stakeholders, these initiatives do not display in the practice the features of a collaborative model of social dialogue, because the level of involvement of stakeholders in VET, especially the business sector, still lacks the desired intensity and quality. The reasons for this can be found in the insufficiently specified role (competences/ responsibilities, benefits), in the legislative framework, poor motivation of the business sector for cooperation, the economic crisis which destabilised collective initiatives, shortcomings in the work of the professional institutions and bodies, shortcomings in the systemic set-up of VET, etc. Taking all this into account, the practicing of the social dialogue in VET is more declarative than collaborative by nature.

The huge impact of globalisation on the Euro-Atlantic aspirations of the country, access to best practices from developed countries, high unemployment and the need for enhanced economic development have all highlighted the role of VET in the country's development. Questions of quality of VET and its relevance to the labour market and life in general have become topics of debate in a number of expert and public debates, meetings and conferences. The need for youth and adults to through education acquire "new" skills - adequate for the "new age" emerged above all from the reaction of the business sector, clearly stating the demand for redefining the role of stakeholders in the creation and implementation of VET policies.

The opinion that education and labour should pursue an interactive relationship, which has been voiced for a number of years by the expert community, is slowly becoming the opinion of the business community as well. This is a natural evolutionary process where the need changes the opinion and behaviour. For many years the business community has been a passive recipient of VET system "deliverables", without showing any initiative and taking a proactive role in the production of "new" workers. Faced with the challenges of new technologies and the need for workers with appropriate skills sets, the business community has focused its interest on education and voiced its demands for its greater rel- evance.

In parallel, dynamic changes in life brought to the forefront the need for VET to not only prepare quality workforce but also active citizens, "armed" with skills for lifelong learning and prepared for national and international mobility. This clearly made the point that VET is not an issue of central government, but one that affects all stakeholders.

In establishing necessity as a driving force for changing the reality, the need for redefining the architecture of social dialogue in the country was highlighted. It has become evident that it is not sufficient only to have a legislative framework which provides for participation of stakeholders in the creation and realisation of VET policies, but that what is needed are mechanisms for their active involvement, which can yield good results in the practice. This represents the foundation for the application of the collaborative model of social dialogue in VET.

Several initiatives have been undertaken in the country in recent years for establishing a collaborative model of social dialogue in VET. Most characteristic examples for the practice of collaborative model are the evaluation of VET reforms and the development of the VET Strategy and Action Plan in the context of lifelong learning, carried out between April 2012 and March 2013. The project supporting the development of this country strategy was supported by ETF as a response to the needs for collaboration expressed by the Ministry of Education and Science and the VET Centre. (ETF, 2010: Collaborative evaluation of the impact of the reformed 4-year secondary vocational education, Skopje)

\section{MATERIALS AND METHODS}

\author{
Report on the collaborative approach of \\ the VET strategy process
}

The Country Strategy for Vocational Education and Training in a Lifelong Learning Context is aimed at strengthening the attractiveness, relevance and quality of vocational education and training, enabling it to play a major role in the improvement of professional performance, competitiveness and innovation. The future VET system is expected to offer more diversified and flexible learning opportunities to youth and adults to acquire skills necessary for their career development and to stimulate their entrepreneurial spirit, 
whilst fostering participation in further education and training, and contributing to active citizenship and personal fulfilment. The new architecture of VET should promote both excellence and social inclusion, contribute to greater employability, mobility and job security, enhance anticipation and management of labour market shifts and encourage business competitiveness. Vocational education and training policy needs to be geared towards the skills requirements of the labour market and economic sectors, and based on more effective social dialogue in an environment of ever growing international cooperation.

The methodology applied in the development of the Strategy builds on the latest achievements in VET policies and practices in the EU, most notably the Copenhagen, Bruges and Torino processes. Designed as a participative collaborative process, it lead to evidence based analysis of domestic policies and practices in VET and to a set of specific recommendations and practical proposals and a structure for their implementation. The methodology fully reflects the principles of the Torino process:

- importance of ownership, leadership and stakeholder participation, epitomised in the collaborative approach;

- holistic approach linking education, training, employment, economic and social development through, among others, active participation of stakeholders from the education, social and economic field in the process;

- focus on evidence to guide decisions.

The research did not focus only on the breadth, but also attempted to go in-depth into respective issues. This approach was conditioned by the objectives, scope, duration and desired coverage of the research, but primarily by its nature as predominantly qualitative research.

The new VET strategy established a new approach to analysing the situation in VET by applying a collaborative approach. This approach was a relative novelty in the country, as it actively involved all stakeholders in different stages, giving them a developmental role - an opportunity to be consulted and to contribute to the growing pool of evidence and to the final document, and ensuring their opinions are heard and input valued, thus enhancing their sense of ownership and accountability for the final product. Through outcome-based research, consultations and analyses, the consultation process resulted in an extensive evidence base on the quality and relevance of the VET from the perspective of a broad base of stakeholders.

The consultation efforts of stakeholders were an excellent example of a collaborative, systematic and interactive process involving VET clients, stakeholders and policy-makers for the purpose of exchanging information, initiating and addressing specific pertinent issues, discussing alternative solutions, and devoting effort to overcoming differences. All stakeholders participating had the right and expectation to be consulted, since the proposals and policies under review impact greatly their life and work, and it is them who are expected to implement or contribute to the new policies and practices.

\section{RESULTS AND DISCUSSIONS}

Lessons for future policy and practice of social dialogue and partnership in VET

The experience from the stakeholder consultation activities within the process of development of the Strategy for VET in the context of lifelong learning allows us draw some lessons that might contribute to the strengthening of the collaborative model of social dialogue in VET in the country. Certain aspects, if kept in mind, will help improve the quality of process and outcomes of social dialogue.

\section{When to start?}

Social dialogue is not an activity to be ticked off as completed, but rather a process permeating all actions undertaken, from the very first to the very last. It proved useful that the Launch of the Project was used for awareness raising on the importance of social dialogue and for lobbying with and selection of appropriate stakeholder representatives who would take part in it. To this end, the professional integrity of the process and the team leading it also contributed to various stakeholders understanding the ethos of the process and committing to it. Also, the planning process needed to be adapted to the specificities of the dialogue partners and take into account their schedules; their involvement outweighs the rigidity of any plan, even the best.

It is to be expected and hoped that the dialogue will continue well beyond the adoption of the VET Strategy and Action plan. It will be a crucial tool for ensuring and monitoring the implementation and evaluating the 
impact. It is exceptionally important that the stakeholders remain partners, and have a place on the Strategy Council or whatever other or additional national or local structure is created to support the implementation of the VET Strategy.

\section{Who to involve?}

The work of the Stakeholder Steering Group, through the participation of different ministries, institutions and professional bodies, provided the necessary intersectoral mechanism in the development of the Strategy. It was crucial during the selection of the representatives to secure the involvement of individuals with professional background, who were familiar with the problems of VET within their area of operation, but were also in a position to speak on behalf of their institution/sector and to ensure an internal flow of information, findings and recommendations to and from higher decision making instances.

In regard to the selection of participants in the social dialogue, it was important to ensure that the stakeholders involved represented not only their own interests, but also had the necessary competence and knowledge, and trust of those they represented to speak and listen on their behalf. The vertical/hierarchical representation of the stakeholder basis, including highest level of policy-makers as well as practitioners, large companies and chambers as well as small local business, gave the social dialogue the necessary legitimacy. Involvement of dedicated organisations and non-partisan individuals, with proven track record of advocating for the interests of those they represent, but also with familiarity of the topic at hand, are a guarantee that the outcomes of the dialogue will not only be acceptable to others, but will contribute not only to the improvement of the quality, relevance and attractiveness of the future VET system, but also of the sense of ownership and accountability for the process. The selection of regions where the social dialogue was conducted ensured equitable representation of various stakeholders in regard to their geographic, regional, ethnic, occupational, financial, etc. background.

In this sense, it is also important that the expert team members possess the necessary expertise and experience not only in VET but also in management of consultation processes, and also have professional integrity and have earned respect of the partners in the dialogue.

\section{How to proceed?}

The organisational structure of the process of development of the Strategy created a vertical link and communication between the highest state champions and institutions, through the professional bodies and agencies and VET schools to the VET clients - the employers. The basic difference between this and other research lies precisely in its collaborative nature, with active involvement of a number of equal partners with clearly defined interests and objectives, but open to take in other perspectives in a process of consensual identification of national priorities and strategic directions.

One of the elements ensuring the participation and contribution of key partners and interlocutors was the support from MoES, ETF and the VET Centre. The Letter of Endorsement issued by the State Secretary of Education, albeit with delay, provided the necessary leverage and assurance that this process would result in tangible positive effects for all concerned and involved. One of the strong points of this process was the recognition from the beginning, that the greatest added value towards quality of the Strategy and ownership of the process was the enhanced social dialogue as a mechanism for its development, which was made clear in the support from the highest decision-making instances.

Collaborative approach and social dialogue are possible only if the involved parties take ownership of the process and view it as "developmental", and not as an attempt to detect "weaknesses" in their work. This is valid for the state institutions and professional VET bodies as well as for all the others (VET schools, teachers, students, employers, universities, chambers, employment services, etc.). Therefore, those responsible for the consultation process must be careful in how they approach the involved parties and design the instruments. The development dimension must be strongly and clearly emphasised, and any element that could possibly cause fear or criticism of the involved must be eliminated.

Social dialogue through the collaborative approach required direct contact and consultation with stakeholders on "their turf" and gaining insight into the current situation, their work, problems, needs and desires. The involvement of a larger group and various types of stakeholder representatives (expert institutions and bodies, students, teachers, managers, employers, local government, local and national employer associations and chambers 
of commerce and crafts, local and central Employment Service Agencies, NGOs, international donors, institutions etc.) eliminated the weaknesses of a "delegation" approach, where it is questionable whether the individuals actually represent the interest of the sector or the institution and whether a two-way flow of information and knowledge is ensured. The democratic participation of the main stakeholders in VET, both provided them with a sense of importance and strengthened their ownership, and also provided them with a direct opportunity to exert influence over decisions that affect them in a matter of joint interest. This is the essence of social dialogue.

\section{What to be keep in mind?}

Each collaborative process faces the problem of "ascertaining the truth". There is a threat for the consultations to be carried out with individuals, inappropriately delegated to represent key stakeholders, who are not familiar with the issues in VET. Their opinions in regard to VET do not correspond to the reality, lack argumentation and may misguide the process of decision-making. Another threat lies in the possibility for different versions of the "truth" presented, when a party puts its own interests above those of others or the community, or even the country. Special care should be taken to carefully exam such contributions, reflect on and triangulate them against other input, and select those contributions that are demonstrably aimed at improving the quality of both the VET Strategy and the system it aims to establish.

Another issue to be cognisant of is the question whether collaborative consultation process or social dialogue at the same time includes collaborative writing. It is to be expected that parties would like greater attention focused on issues pertinent to their area of work or influence. In the VET Strategy development process, it was important to have the initial findings presented to the stakeholders, incl. policy makers, expert bodies, VET schools, employers and their associations, local government etc., in an open and active dialogue, so that the findings could be verified and validated, to avoid later questions about their validity. In addition, the Minister's expert review group provided a clear focus and legitimacy for policy decisions, helping avoid possible interests or influence, and ensuring that they reflect the intentions and directions of the highest decision-making levels.

\section{CONCLUSIONS}

Process of governance in VET globally operates on a multi-level and between multistakeholders, and the latest improvements in the legislative framework of VET testify to the country's efforts for systematic involvement of the key stakeholder communities, local authorities and relevant state agencies in the process of policy development, implementation and review.

It is important in the coming period to intensify social dialogue in the country in the processes of VET governance. The role of stakeholders dominantly positioned in implementation or use of the outputs of the VET system, needs to be upgraded through their participation in policy-making and management in VET. This will strengthen their active participation and the degree of their accountability for VET interventions and their effects.

The role of the business sector in decision-making and management of VET providers and their quality assurance processes should be improved with the adoption of legislative measures and application of new collaboration models and mechanisms. The status of the business sector as a stakeholder should evolve into that of a partner in VET

Funding for the public secondary VET system is provided by the Government. Enhanced efforts are needed for attracting and benefiting from diverse funding sources and schemes, and mechanisms should be developed for their utilisation as "models of costsharing between different partners in the educational process - the state, businesses and individuals, foundations and alumni - with public investment helping to leverage private sector match-funding”. (ETF, 2010: Collaborative evaluation of the impact of the reformed 4-year secondary vocational education, Skopje)

The introduction of a training fund in the state budget presents an efficient tool for strengthening the participation of youth and adults in education and training for acquisition of qualification and/or retraining. The training fund can have as its source a percentage of the personal income tax, a percentage of the overall revenue of the business entity, external assistance (European funds, donors, etc.), joint investment by the government and the private sector, etc.

In the context of devolution of responsibilities, local governments should be encouraged, and on their part interested, to secure additional resources to support local VET de- 
velopment, and companies "should increase investment in initial VET notably through their involvement in alternative training models, but also by supporting schools with adequate equipment". (European Commission: Communication from the Commission to the European Parliament, the Council, the European Economic and Social Committee and the Committee of the Regions: Rethinking Education: Investing in skills for better socioeconomic outcomes, Strasbourg, 20.11.2012, COM (2012) 669 final)

Education providers themselves should be encouraged to, and rewarded for, initiating and developing additional income generation activities, which whilst ensuring staff are remunerated and motivated for additional efforts, should also be used to improve the quality and relevance of education and training provided to all beneficiaries throughout the institution, and also to intensify the social dialogue with the business sector and local government.

Social dialogue in VET should be set up according to the principle of functionality and based on the principle of partnership. The role of social partners in VET needs to be effectuated through their active role in policy creation, and development and management of VET.

The business sector needs to find its own interest in the VET system and in the process of development of education policies. It must transform itself from an indifferent into a critical partner of VET providers, agencies and the state.

\section{Conflict of interests}

Authors declare no conflict of interest.

\section{REFERENCES}

ETF (2010). Collaborative evaluation of the impact of the reformed 4-year secondary vocational education, Skopje.

European Commission (2012). Communication from the Commission to the European Parliament, the Council, the European Economic and Social Committee and the Committee of the Regions. Rethinking Education: Investing in skills for better socio-economic outcomes, Strasbourg, COM (2012), 669 final.

Humpl, S., \& European Educational Research Association. (2007). Quality assurance in VET and HE: possibilities for mutual learning. Paper based on the Final report of the DEQU Enhancing Quality in Practice Orientated Higher Education v External Stakeholders and the Relevance of Curriculum Project, Ghent Conference.

Law on oriented vocational education, Official Gazette of the Republic of Macedonia No. 16 from 22 May 1985.

Law on Vocational education and training, Official $\mathrm{Ga}$ zette of the Republic of Macedonia No. 71 from 08.06.2006.

Statistical Yearbook of the Republic of Macedonia, 1992. 